\title{
Study on the Efficiency of Fractures Treated With Proximal Femoral Locking Compression Plate
}

\section{Ravi G.0 1, Shaik Hussain Saheb *2.}

${ }^{1}$ Assistant Professor Department of Orthopaedics , JJM M edical College, Davangere, Karnataka, India.

${ }^{* 2}$ Assistant Professor Department of Anatomy, JJM M edical College, Davangere, Karnataka, India.

\section{ABSTRACT}

Background: Extracapsular fracture neck of femur are common in moderate to high velocity injuries Fracture union is not a great problem due to proximal femoral anatomy. The primary goal of treatment is early mobilization to avoid secondary complications which may arise due to conservative treatment and due to other co-morbid complications of prolonged immobilization This can be achieved by proximal femoral locking compression plate,This allows early weight bearing and has a lower complication rate than other implants. The basic aim of present study is to observe the efficiency and outcome of fractures treated with Proximal Femoral Locking Compression Plate.

Materials and Methods: This is a prospective study of 21 cases of Extra capsular fracture neck of femur admitted to Victoria and Bowring and Lady Curzon Hospitals, Bangalore. treated with Proximal Femoral Locking Compression Plate (PF-LCP).

Results: In our study of 21 cases, cases 13 cases were intertrochanteric fracture and remaining 8 were subtrochanteric fracture with the mean age was 51.47 years. 13 patients (62\%) had right-sided fracture and 8 patients (38\%) had left-sided fracture. with right side being more common side affected. The average duration of stay in the hospital was 25 days; the average follow up was 18 months. Out of 21 patients in our study 16 patients (76\%) are able to sit cross-legged and can squat on ground without any problem.

Conclusion: In conclusion the potentiality of the Proximal Femoral Locking Compression Plate (PF-LCP) in varied indications shows its versatility. Although not free of complications our study has demonstrated excellent results. The procedure offers, faster mobilization, rapid return to activities of daily living, improves the quality of life and gave a long term solution in patients with extra capsular fracture neck of femur.

KEY WORDS: Intertrochanteric fractures, Subtrochanteric fracture, Proximal femoral locking Compression plate.

Address for correspondence: Shaik Hussain Saheb, Assistant Professor, Department of Anatomy, JJM M edical College, Davangere, Karnataka, India. M obile No.: +91-9242056660

E-Mail: anatomyshs@gmail.com

\begin{tabular}{|c|c|c|}
\hline \multicolumn{3}{|c|}{ Online Access and Article Informtaion } \\
\hline \multirow{2}{*}{$\begin{array}{c}\text { Quick Response code } \\
\text { Dol: } 10.16965 \text { ijims.2015.131 }\end{array}$} & \multicolumn{2}{|c|}{$\begin{array}{l}\text { International Journal of Integrative Medical Sciences } \\
\text { www.imedsciences.com }\end{array}$} \\
\hline & $\begin{array}{l}\text { Received: 17-10-2015 } \\
\text { Reviewed: 17-10-2015 }\end{array}$ & $\begin{array}{l}\text { Accepted: 02-11-2015 } \\
\text { Published: 30-11-2015 }\end{array}$ \\
\hline Source of Funding: Self & \multicolumn{2}{|c|}{ Conflicts of interest: None } \\
\hline
\end{tabular}

\section{BACKGROUND}

Extracapsular fracture neck of femur are common in moderate to high velocity injuries Fracture union is not a great problem due to proximal femoral anatomy. Unlike intracapsular fractures of neck of femur, there is no fear of complications like, avascular necrosis of head and its sequalae of osteoarthritis. Though trochanteric fractures can unite without surgical intervention, malunion with coxavara deformity resulting in shortening of limb and limp are commonly seen. Until operative treatment involving the use of various implants was introduced In the 1950s, hip fractures were managed using 
conservative methods based on traction and bed rest.

Various operative procedures with different implants have been described for the treatment of extracapsular neck of femur fractures. Earlier active treatment was usually delayed for as long as three to four weeks because it was believed that attempts to immobilize the limb by splints traction or open reduction with internal Fixation would prove fatal but this usually leads to secondary complications like varus deformity. The primary goal of treatment is early mobilization to avoid secondary complications which may arise due to conservative treatment and due to other co-morbid complications of prolonged immobilization; this can be achieved by proximal femoral locking compression plate. This allows early weight bearing and has a lower complication rate than other implants.

The Extra capsular fracture neck of femur are relatively common injuries in adults. The Intertrochanteric fractures in younger individuals are usually the result of a high-energy injury, such as a motor vehicle accident (M VA) or fall from a height. Ninety percent of intertrochanteric fractures in the elderly results from a simple fall. In elderly patients with intertrochanteric fractures most of them have considerable osteopenia, with the quality of bone for the purchase of fixation within the femoral head and neck less than desirable Hence it is important that the internal fixation device be placed in that part of the head and neck where the quality of bone is good and the implant and bone fixation should be rigid and stable. The most important goal of operative treatment is strong, stable fixation of the fracture fragment. Trochanteric lateral plate is superior to a compression hip screw to support the lateral aspect of the greater trochanter in unstable fractures. This aids in resisting lateral sliding of the proximal fragment and maintaining an anatomical reduction. The Skin, fat, and muscles surrounding the hip can absorb large amounts of energy from an impact. The age-related decline in muscle mass around the hip may account for the increased incidence of hip fractures with aging. Furthermore, because the reaction times are longer and muscle strength less, older persons' protective responses tend to be too little and too late.
Operative management, which allows early rehabilitation and offers the patient the best chance for functional recovery, is the treatment of choice for the vast majority of intertrochanteric fracture [1].

\section{MATERIALS AND METHODS}

Prospective study of adult patients of either sex having an extra capsular fracture neck of femur; who were admitted to Victoria hospital and Bowring \& Lady Curzon hospital attached to Bangalore Medical College \& Research Institute, Karnataka, India. The Inclusion criteria, Male $\&$ Female adult patients aged more than 18 years, Patients with proximal femoral fracture including intertrochanteric fracture, sub trochanteric fracture with varying degrees of comminution. Patients who are medically fit for surgery and who have given their written informed consent for the procedure. The Exclusion Criteria, Intra capsular Fracture neck of femur, Fracture more than $7.5 \mathrm{~cm}$ below the lesser trochanter, Patients less than 18 yrs of age, Patients not willing for the surgery, Patients medically unfit for surgery. The M icrosoft Excel software was used for data entry and analysis. Surgery was performed under spinal anesthesia/ Epidural anesthesia/GA Surgery was closed reduction and internal fixation with proximal femoral locking compression plate (PFLP) for an extra capsular fracture neck of femur. Postoperatively, no immobilization was used. Third generation Cephalosporin were used 24 hours preoperatively, intraoperative and postoperatively, and oral antibiotics till suture removal. The patients were followed postoperative an average of 18 months.

\section{RESULTS}

In our study of 21 cases, cases 13 cases were intertrochanteric fracture and remaining 8 were subtrochanteric fracture with the mean age was 51.47 years. 13 patients (62\%) had right-sided fracture and 8 patients (38\%) had left-sided fracture. with right side being more common side affected. The average duration of stay in the hospital was 25 days. The average follow up was 18 months. Out of 21 patients in our study 16 patients (76\%) are able to sit cross-legged and can squat on ground without any problem. 
Table 1: Showing the results after Fractures Treated With Proximal Femoral Locking Compression Plate.

\begin{tabular}{|c|c|c|c|c|}
\hline Results with Harris Score & $\begin{array}{c}\text { No of } \\
\text { patients }\end{array}$ & $\%$ & $\mathbf{X}^{2}$ & P \\
\hline Excellent (91-100) & 10 & $48 \%$ & & \\
\cline { 1 - 3 } Good (80-90) & 8 & $38 \%$ & \multirow{2}{*}{11.19} & \multirow{2}{*}{0.011} \\
\hline Poor (60-70) & 2 & $10 \%$ & & \\
\hline Failure (60) & 1 & $5 \%$ & & \\
\hline
\end{tabular}

\section{DISCUSSION}

Fixation of intertrochanteric fracture has evolved through various implant devices where as dynamic hip screw is the most practiced and established implant followed by proximal femoral nail which is an Intramedullary device. The following implants have their own limitations in comminuted fractures especially with lateral cortex fractures, sub trochanteric fractures and with co existing osteopenia. In our present study, inter trochanteric fractures and sub trochanteric fractures have been considered in this study. 13 cases were intertrochanteric fractures. Among them 7 patients were males and 6 patients were female, 8 patients had right side injury and 5 patients had left side injury. The remaining 8 patients were sub trochanteric fracture. This included 7 males and 1 female with 5 patients having had right sided and 3 patients had left sided fracture.

Extracapsular fractures occur mainly in adults and showed the same patterns but the mean age differed in few depending on the number of the fractures studied. Studies by Emily Banks et al [2] in 2009 showed mean age of 70 years. The mean age of the patients was 75 (48-93) years in anatoher the study [3] in 2011. In study by PhilipJ Glassner et al [4], the average patient age was 56.7 years (range, 36-72 years). Andres $P$ et al [5] study had an average age of 75.8 years. The mean age observed in our study was 51.5 years. The youngest in our study was 19 years and the oldest was 85 years old. We had $43 \%$ of patients below 50 years of which most of them had a history of RTA or significant injury. Gender specificity shows more preponderance towards female to sustain these fracture than male. This is due to vulnerability of female because of postmenopausal osteopenia and related factors. Zha ZeLin Chen et al [3] in 2011 had 72 females and 38 males in their study, Wang Yet al [6] in 2011 had 23 males and 19 females out of their 42 patients. Ecker et al [7] observed $82 \%$ of female gender and $18 \%$ of males in their study. Of the 21 cases studied 14 patients (67\%) were males and 7 patients (33\%) were females. $48 \%$ in the present series had an history of road traffic accident as the mode of injury of which all were males except one female (case 20). 4 patients (Females) (19\%) had trivial trauma. 2 patients (female) (10\%) had self fall, one from his bike. We had 2 males (10\%) with history of fall from a height. Patients below 50 years were all males and all had significant mode of injury. This may explain the male preponderance fractures in our study.

Boyd and Griffins [8] classifications for trochanteric fractures is used in the study. In our study, 11 patients presented with Type II fractures and 2 patients with Type III fractures making total of 13 intertorchanteric fractures, which is found to be statistically significant. Seinsheinmer's Classification is used for Subtrochanteric fracture of which 2 patients are of type $3 A$ and 5 patients are of type 4.5 patients in our series had associated injuries. The injuries were fracture of both pubic rami, distal radius fractures, multiple rib fractures, $3^{\text {rd }} \&$ $4^{\text {th }}$ metacarpal fractures in different patients. All the associated fractures were managed appropriately. Co-morbid conditions observed was hypertension in 3 cases (14\%), diabetes mellitus in 2 cases (10\%), one case of Anemia $(5 \%)$ and pulmonary tuberculosis $(5 \%)$ which was treated accordingly. The average duration of stay in the hospital was 25.31 days with minimum stay of 10 days to maximum of 46 days. This was due to time taken for treatment of pre existing diseases, scheduled operating days in the hospital, delay of procurement of implants by the patients, time taken for post op recovery and rehabilitation in wards. In the studies of Malcolm. L, Ecker et al [7] it was 25.9 days, Richard F. Kyle et al [9] was 18 days and G.H.Yeyse M oore et al [10] hospital stay was 21 days. Judicial use of preoperative traction reduces the pain and improves the compliance of the patient. Above knee skin traction was used in $38 \%$ ( 8 cases) of the cases that were planned for an early surgery. $62 \%$ ( 13 cases) of them had to undergo upper tibial skeletal traction as the surgery was delayed for one or many of the 
reasons mentioned earlier. Finsen [11] in 1992 found that there was no difference in the time taken to reduce the fracture or the length of operating time by preparative traction. In 1998 Resch [12] compared skin traction versus skeletal traction. $50 \%$ of skeletal compared with $20 \%$ of skin traction group. He also found no difference between the two groups as he stated that many patients found the application of skeletal traction painful both Finsen [11] 1992 and Resch [12] 1998 reported no significant difference in the length of operation.

Post operative weight bearing status was dependent on fracture pattern. Stability at fixation, osteoporosis and general well being of the patient. Compliance of the patient was also taken into consideration. Touchdown weight bearing to Partial weight bearing was allowed from day 1 to 8 weeks. Further partial weight bearing to full weight bearing was allowed between 8 weeks to 12 weeks depending upon the fracture healing and other associated factors. In our series 16 patients started partial weight bearing till 8 weeks and 5 patients started delayed partial weight bearing at 12 weeks. Full weight bearing started at 16 weeks in 16 patients and 5 patients started at 20 weeks. The functional results were graded according to Harris Hip Scoring System, where in, a score of 91-100 for excellent results, 80-90 being good, 70-79 fair, 60-69 poor, and below 60 a failed result. In our study, 10 patients (48\%) had excellent results, 8 patients (38\%) had good results, 2 patients (10\%) had poor result, and 1 case was considered as failure $(5 \%)$. This particular patient is an elderly female of 85 years and her pre injury activities of daily life were grossly limited and dependant and her mobility was not independent. In their study Shao-hongl, WANG Wei-lin et al 2011 showed that Harris hip function score was excellent in 24 cases, good in 20 cases, and poor in 4 cases [13]. M inghua XI E Wenweiet in 2011observed an Harris score results were excellent ( $\geq 90$ score) in 22 cases showed good(80-89 score) [14].

\section{CONCLUSIONS}

In the present study of PF-LCP, performed for extracapsular fracture neck of femur in 21 patients, at Victoria Hospital, Bowring and Lady
Curzon Hospital, the procedure offered an excellent pain free mobile hip, with easy rehabilitation and rapid return to functional level, when standard techniques were used. The potential of the PF-LCP in varied indications shows its versatility. Although not free of complications our study has demonstrated excellent results. The procedure offers faster mobilization, rapid return to activities of daily living, improves the quality of life and gave a long term solution in patients with extra capsular fracture neck of femur. Larger studies with longer follow up will further validate the procedure.

\section{REFERENCES}

[1]. Wong PCN. Femoral neck fractures among the major racial groups in Singapore. Incidence pattern compared with non Asian communities. Singapore Med. 1984;5:150-157.

[2]. Emily Banks, Gillian K. Reeves, Valerie Beral, Angela Balkwill, Bette Liu, Andrew Roddam, and for the Million Women Study Collaborators Hip Fracture Incidence in Relation to Age, Menopausal Status, and Age at M enopause: Prospective Analysis. PLoS Med. 2009;6(11):e1000181.

[3]. Zha ZeLin Chen, Zhongguo Gu Shang. Wang Y, Yang YY. Comparative study of intertrochanteric fractures treated with proximal femur locking compress plate in aged Source Hospital of Integrated Traditional and Western medicine of Wenzhou. 2011; 24(5):370-3.

[4]. Philip J Glassner, Nirmal C Tejwani Failure of proximal femoral locking compression plate: $\mathrm{A}$ case series. Journal of orthopedic trauma. 2011;25(2):76-83.

[5]. Anders Enocson, Leif Mattisson, Carin Ottosson, and Lasse J Lapidus. Hip arthroplasty after failed fixation of trochanteric and subtrochanteric fractures. Acta Orthop. 2012; 83(5): 493-498.

[6]. Wang Y, Yang YY, Yu ZH, Li CQ, Wu YS, Zheng XX. [Comparative study of intertrochanteric fractures treated with proximal femur locking compress plate in aged]. Zhongguo Gu Shang. 2011;24(5):370-3.

[7]. Ecker Malcolm L.et.al. Treatment of trochanteric hip fractures using compression screw. J Bone Joint Surg, 1975;57:23-27.

[8]. Boyd HB, Anderson LD. Management of unstable trochanteric fractures. Surg Gynecol Obstet. 1961;112:633.

[9]. Richard F. Kyle, M D; Jessica Cooper, M D. Total Hip Arthroplasty After Failed Fixation of Hip Fractures. Orthopedics. 2006;29(9):783.

[10].G.H. Yeyse Moore etal. Treatment of intertrochanteric fractures of the femur: a comparison of the Richards screw-plate with the Jewett nail-plate. J Bone Joint Surg (Br). The Bone \& Joint Journal 1983;65(3):262-7. 
Ravi G.O, Shaik Hussain Saheb. Study on the Efficiency of Fractures Treated With Proximal Femoral Locking Compression Plate.

[11]. Finsen V, Borset M, Buvik GE, Hauke I. Preoperative traction in patients with hip fractures. Injury 1992;23(4):242-4.

[12]. Resch S, Thorngren K-G. Preoperative traction comparison between skin and skeletal traction in 78 patients. Acta Orthopaedica Scandinavica 1998;69(3):277-9.

[13]. Shao-hong,WANG Wei-lin, et al. A comparative study of locking compression plate and Dynamic Hip Screw in Treatment of Femoral Intertrochanteric Fractures. Guide of China M edicine 2011-15 Latest Update.
[14]. M inghua XIE Wenwei YAO Hangan et al. Efficiency Analysis of proximal femoral Locking Plate for the Treatment of Intertrochanteric Fractures.China Foreign M edical Treatment. 2010-12 Latest Update.

How to cite this article:

Ravi G.0, Shaik Hussain Saheb. Study on the Efficiency of Fractures Treated With Proximal Femoral Locking Compression Plate. Int J Intg Med Sci 2015;2(11):191-195. DOI: 10.16965/ijims.2015.131

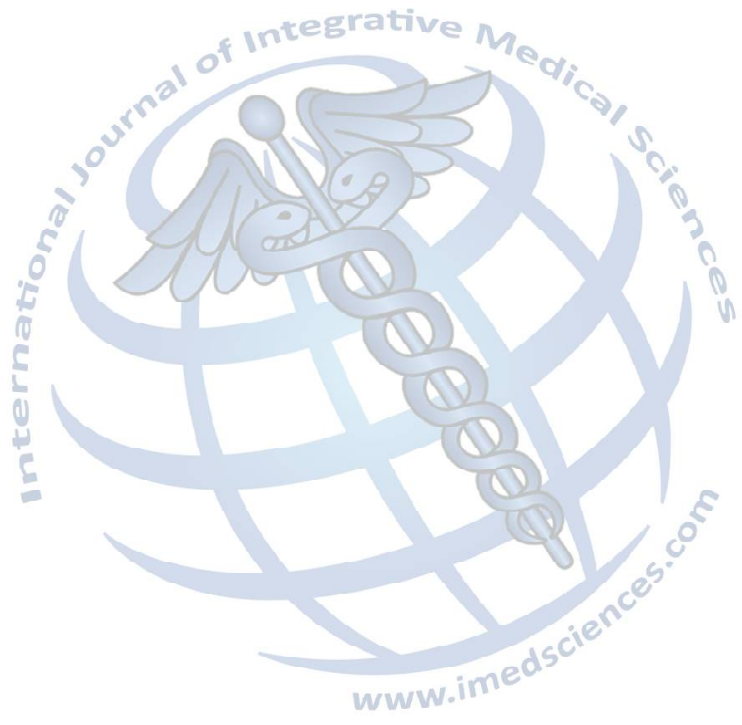

